\title{
A prevenção primária e a detecção do câncer de estômago
}

\author{
Primary prevention and detection of gastric cancer
}

Evaldo de Abreu 1

1 Coordenadoria de Programas de Controle do Câncer, Instituto Nacional de Câncer. Av. Venezuela 134, bloco A, 9o andar, Rio de Janeiro, RJ 20081-310, Brasil.
Abstract Stomach cancer, the world's most common malignant neoplasia in 1980, has shown a decrease in death and incidence rates in several countries. Still not totally elucidated, the decline in inci dence and death rates has been attributed to environmental factors. It is unlikely that the decline has stemmed primarily from changes in either the treatment system or diagnostic techniques. In Brazil, stomach cancer has been a major challenge, since the country faces high incidence and death rates. In addition, the Brazilian heal th system lacks the means to assume, fund, and devel op a stomach cancer diagnostic program. According to current knowledge, stomach cancer devel ops from damage to the gastric mucosa by a diet rich in salt, nitrates/nitrites, and possibly carbohydrates. Initiation and development can be offset by a sufficient intake of fruit and fresh vegetables. Household refrigeration, widespread since the early 20th century, has hel ped people consume fresher, well-preserved food, no doubt generating a major downward impact on stomach cancer rates. In present-day Brazil, a national policy aimed at stomach cancer control must be based on rebuilding the health system and expanding patients' access to it, disseminating information on diet changes, and improving soci oeconomic conditions.

Key words Cancer; Cancer of Stomach; Risk Factors; Prevention; Epidemi ology

Resumo O câncer de estômago, a neoplasia maligna mais comum no mundo em 1980, vem apresentando uma diminuição da incidência e mortalidade em vários países. Este declínio tem si do atribuído a fatores ligados ao ambiente. É improvável, porém, que ele tenha resultado de mudanças no sistema de atendimento ou nas técni cas de diagnóstico. No Brasi l, o câncer de estômago constitui-se num dos maiores desafios, pois as suas inci dência e mortali dade são ascendentes, e o nosso sistema de saúde encontra-se desestruturado para assumir e desenvol ver um programa de detecção, de altíssi mo custo. Este ti po de câncer surge a partir de danos causados à mucosa gástrica por uma dieta rica em sal, ni tratos, ni tritos e, talvez, carboi dratos. Suas iniciação e progressão podem ser neutralizadas por uma adequada ingestão de frutas e verduras frescas. A refrigeração, difundida a partir do início deste século, levou as pessoas a consumi rem alimentos mais bem conservados e frescos, o que certamente causou um grande impacto sobre o declínio da incidência do câncer gástrico. No Brasil de hoje, uma política nacional voltada para o controle do câncer de estômago tem de ser baseada na reestruturação do sistema de saúde e do acesso das pessoas a ele, na difusão de informações rel ativas à mudança de hábi tos ali mentares e na melhoria das condições sócio-econômicas.

Palavras-chave Câncer; Câncer de Estômago; Fatores de Risco; Prevenção; Epidemiologia 


\section{O câncer de estômago no mundo}

A mortalidade por câncer de estômago exibe uma definida graduação sócio-econômica, sendo as taxas nos grupos sociais mais baixos aproximadamente o dobro da verificada nos estratos sócio-econômicos superiores.

Em 1980, o câncer de estômago era a neoplasia maligna mais comum no mundo, porém, com o declínio de 2,2\% ao ano observado nas suas taxas de incidência e com o aumento da freqüência do câncer de pulmão, aquela situação modificou-se. A diminuição das taxas de incidência e mortalidade, que se tem verificado em vários países, apresenta-se maior nos Estados Unidos da América. Este fato vem chamando a atenção desde 1940, quando o câncer de estômago era a principal causa de morte por câncer entre homens, e em 1970 já ocupava a sexta causa de morte por câncer em ambos os sexos. Atualmente, naquele país, onde o câncer de estômago representa apenas 2,8\% de todos os casos novos de câncer registrados, esta neoplasia deixou de ser prioritária, e não têm sido propostas medidas de controle para este tipo de câncer, em parte pelo declínio, ainda inexplicável, da incidência e da mortalidade, e também por não existirem medidas práticas de prevenção a serem adotadas para esta neoplasia.

O declínio da mortalidade por câncer de estômago, sobejamente verificado em todo o mundo, é mais atribuído a fatores ligados ao meio ambiente do que genéticos, eé improvável que o marcado declínio da sua incidência tenha resultado primariamente de mudanças no sistema de atendimento ou nas técnicas de diagnóstico. É igualmente improvável que o declínio da mortalidade, internacional mente observado, tenha se devido exclusivamente a melhor deteç̧ão precoce e gerenciamento médico-hospitalar, uma vez que o prognóstico, exceto nos estágios muito iniciais da doença, permanece relativamente pobre.

O Brasil e seu sistema de saúde em face do câncer de estômago

Um programa de detecção do câncer de estômago exige um sistema de saúde bem estruturado, envolvendo os três níveis de assistência, que necessitam estar equipados e perfeitamente entrosados entre si. Nesse sentido, podemos afirmar que o câncer de estômago constitui-se num dos maiores desafios com que se defronta a Cancerologia no nosso país, pois, ao lado de contarmos com uma elevada incidên- cia - o câncer de estômago é o tumor mais incidente em Belém (1989) e Fortaleza (1985), o segundo em Campinas (1992) e o terceiro em Porto Alegre (1991) e Goiânia (1991) entre os homens; entre as mulheres, é um dos cinco cânceres mais freqüentes em todas as regiões do país -, o nosso sistema de saúde encontra-se desestruturado para assumir e desenvolver um programa de detecção do câncer de estômago. Por outro lado, um programa de detecção é de altíssimo custo e requer a participação de profissionais médicos e de enfermagem altamente qualificados mediante treinamento geralmente de longa duração, que envolve a utilização de equipamentos sofisticados, de custo de aquisição e manutenção elevado, e, por essas razões, difíceis de serem difundidos da forma exigida por um programa de detecção em massa.

Um programa desses, portanto, dificilmente poderia ser implementado num país como o Brasil, onde os níveis primário e secundário do sistema de saúde são deficitários. Aqui, programas de detecção extremamente mais simples e de custo final muito mais baixo, como, por exemplo, o da detecção do câncer do colo uterino por meio do exame citológico de Papanicolaou, ainda encontram inúmeras dificuldades de implantação (que se reflete, no caso do câncer do colo do útero, na baixa cobertura verificada para este tipo de exame em todo o território brasileiro).

Ademais, como já dito anteriormente, o câncer de estômago se constitui num caso provavelmente único dentro da Cancerologia, por tratar-se de uma neoplasia maligna que vem apresentando, ao longo das últimas décadas, um declínio progressivo de incidência e mortalidade, declínio este que tem se manisfestado de forma espontânea, sem que se tivesse estabelecido, com exceção do Japão, qualquer programa ou política de saúde que enfatizasse a sua prevenção e diagnóstico precoce.

\section{Prevenção primária}

O conhecimento hoje existente sobre o câncer gástrico sugere ser este uma doença que se inicia cedo na vida do ser humano, na maioria dos casos, provavelmente, a partir do dano causado à mucosa gástrica por uma dieta rica em sal e talvez carboidrato, ou por dieta rica em nitratos e nitritos, já que esta neoplasia incide mais em populações que tradicionalmente utilizam alimentos defumados, conservam alimentos com sal ou em forma de pickles, ou que utilizam alimentos provenientes de solos natural ou artificialmente ricos em nitritos ou nitratos. 
As nitrosamidas, substâncias cancerígenas para a mucosa gástrica, podem ser formadas no estômago humano pela interação entre os nitritos, nitratos e outros substratos do conteúdo gástrico. Também já foi demonstrado que o nitrito aparece em quantidades apreciáveis no suco gástrico humano. A partir de 1925, verificou-se uma redução de cerca de $75 \%$ na utilização de nitrato e nitrito na conservação de carnes, enquanto as taxas mortalidade por câncer gástrico diminuíram dois terços.

Os conhecimentos atuais também indicam que a iniciação e a progressão do câncer gástrico podem ser neutralizadas por uma suficiente ingestão, através dos anos, de frutas e verduras frescas.

Assim, a soma das evidências atuais indica que a adoção de uma dieta prudente e mais realista poderia minimizar os riscos de desenvolvimento do câncer gástrico. Esta dieta seria a que limita a ingestão diária de conservas em vinagre e comidas defumadas, de sal (a 6 - 8 gramas por dia) e de carboidratos (a $60 \%$ do total das calorias), ao lado da ingesta regular de frutas, saladas, e vegetais.

A refrigeração, que teve o seu desenvolvimento e incorporação rapidamente difundidos a partir do início deste século, certamente causou um grande impacto sobre o declínio da incidência do câncer gástrico. A sua adoção levou as pessoas a consumirem alimentos mais bem conservados e frescos, resultando numa ingesta per capita maior de vitaminas C, E, eA, que contribuem como fatores de proteção contra a carcinogênese gástrica, além de ter reduzido a necessidade do uso dos métodos tradicionais de conservação de alimentos com sal e vinagre.

\section{A conservação de alimentos no Brasil}

Dados recentemente divulgados pela imprensa leiga mostram que, no Brasil, a produção e a aquisição de produtos el etrodomésticos ligados ao lazer, como, por exemplo, a televisão, são numericamente superiores às dos produtos chamados de linha branca, como o é a geladeira. A existência de tel evisores em lares brasileiros é superior em quase $10 \%$ à de geladeiras, isto num país de clima tropical e que tem mais da metade da sua população vivendo em regiões onde a temperatura média anual é superior a $\mathbf{2 8}$ graus centígrados.

Econômica e sociologicamente, este fato talvez possa ser explicado de forma um pouco simplista, considerando-se que o televisor ne- cessita, após sua aquisição e instalação, apenas de um simples gesto de se ligar um botão, ao passo que a geladeira requer a existência de um orçamento doméstico capaz de poder suprir e renovar periodicamente o seu conteúdo. Além disso, o primeiro se constitui num fator de lazer para toda a família, lazer este que é o único existente na quase totalidade dos lares brasileiros. Qualquer que seja o motivo, estefato por si só nos aponta para que a preservação de alimentos, e o conseqüente consumo de alimentos mais bem conservados e com um teor de elementos protetores adequados, ainda é muito baixa em nosso país.

\section{O controle do câncer de estômago no Brasil}

Entendemos que uma política nacional voltada para o controle do câncer de estômago tem de ser baseada, além de na reestruturação do sistema de saúde e do acesso das pessoas a ele, também, e mesmo mais, num processo de difusão das informações relativas à mudança de hábitos alimentares. Tal mudança depende da determinação de se avançar na melhoria das condições sócio-econômicas do conjunto da população brasileira, o que certamente possibilitará uma melhor adequação da sua dieta.

Desde a sua criação, há quase dez anos, tem sido norma da Coordenadoria de Programas de Controle do Câncer do Instituto Nacional de Câncer de, ao definir prioridades para o estabelecimento de projetos e programas voltados para a prevenção e a detecção de cânceres, fazê-lo com base em critérios não somente técnicos, mas também políticos. $E$ entendemos que uma política de saúde deve ser, antes de tudo, realista, não devendo jamais basear-se exclusivamente em experiências ou fundamentações oriundas do exterior. O Brasil por si só já representa um país com alto grau de complexidade interna, no qual estados e regiões apresentam desigualdades tão intensas que nos impedem de estabelecer, principalmente na área da Cancerologia, um programa único para o País como um todo, mesmo em se tratando de procedimento com baixo grau de complexidade resolutiva e que apresente um altíssimo grau de difusão e conhecimento, como é o caso específico do exame citológico de Papanicolaou.

No Brasil de hoje, acreditamos que o caminho mais curto e mais efetivo para uma redução da incidência e mortalidade por câncer de estômago passa necessariamente por disporem os lares brasileiros de pelo menos uma ge- 
ladeira, o que certamente depende, em parte, da melhoria das condições sócio-econômicas do País.

A ação governamental deve-se fazer pela política que estimule a produção e o acesso à aquisi ção de refrigeradores e freezerse pela veiculação periódica de um programa educativo de abrangência nacional, com ênfase nos estados onde os registros de incidência vêm mostrando uma maior ocorrência do câncer gástrico, voltado para a prevenção primária e con- substanciado nos conhecimentos existentes sobre os fatores de risco, as condições de risco e os fatores de proteção.

Com base na observação histórica de outros países e de al guns locais do Brasil e nos conhecimentos atualmente disponíveis sobre a gênese do câncer gástrico, este seria inegavelmente o melhor caminho para que, a médio prazo, pudéssemos ver reduzidos os índices de incidência e mortalidade por câncer de estômago atualmente observados no nosso País. 